surface (fig 1). It can then be easily removed with forceps. Alternatively, a formal incision and removal can be done. It is important that all of the larva is removed, as otherwise a local granulomatous reaction can occur.

Simple dressings and antibiotic and tetanus prophylaxis are recommended.
Steffen E. Health risks in short term travellers. In: Travel medicine. Berlin: Springer Verlag, 1989:27-36.

2 Tsuda S, Nagaji J, Kurose K, Miyasotol M, Sasai Y, Yoneda Y. Furuncular cutaneous myiasis caused by Dermatobia hominis larvae following travel to Brazil. Int J Dermatol 1996;35:121-3.

3 Hall M, Wall R. Myiasis of humans and domestic animals. Adv Parasitol 1995;35:257-334.

\title{
Dermatobia hominis in the accident and emergency department: "I've got you under my skin"
}

\author{
A MacNamara, S Durham
}

\begin{abstract}
An unusual form of larval infestation from South America is presented which, in view of increasing tourism to South America's tropical areas, may present to any accident and emergency department. Infestation with Dermatobia hominis is reviewed in terms of clinical recognition and life cycle. Techniques of removal are described. (F Accid Emerg Med 1997;14:179-180)
\end{abstract}

Keywords: Dermatobia hominis infection; treatment

\section{Case history}

Two adults presented to the accident and emergency (A\&E) department of the Leicester Royal Infirmary, having recently returned from a trip to Argentina. Each complained of a single persistently discharging lesion which had been present for several weeks and which had started while they were in Argentina on holiday. In one case the lesion was on the arm and in the other case on the back. They both reported a continuous discharge from the lesions, and that they were not healing. They further reported an alarming sensation of movement within the lesion and occasionally seeing something protrude from the central pore. Physical examination revealed a lesion with raised edges, a central punctum, and surrounding erythema. A serous discharge was noted. A small tube-like structure was noted to protrude intermittently from the central pore.

Discussion with a parasitologist identified the lesions as infestation with Dermatobia hominis. The structure protruding from the lesions was the "respiratory" tube of these air breathing larvae.

\section{Emergency}

Department, Leicester

Royal Infirmary NHS

Trust, Infirmary

Square, Leicester LE1

5WW

A MacNamara

$S$ Durham

Correspondence to:

Mr A MacNamara,

Senior Registrar in A\&E.

Accepted for publication 12 November 1996

\section{The beast}

Dermatobia hominis (human bot fly) is widely distributed throughout Central and South America, attacking a wide range of hosts from poultry through livestock, to man. The species is remarkable for the unique manner in which it delivers its eggs to a new host, by using other insects as carriers or porters. The adult female fly catches and firmly holds another insect,

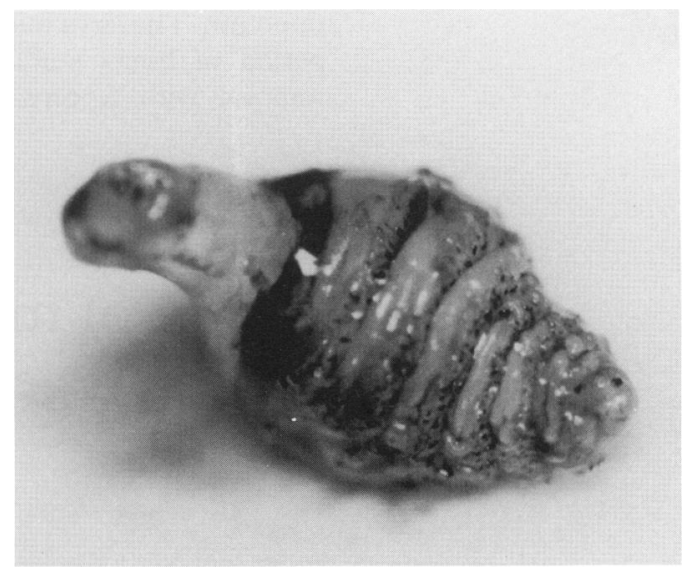

Figure 1 Intact complete larva following removal.

usually a mosquito, and attaches between six and 30 eggs to its abdomen. The larva is very sensitive to temperature changes and remains in the egg shell until it senses proximity to a warm blooded host, whereupon it rapidly hatches and penetrates the host's skin. Each larva penetrates individually, and a small nodule develops around it with a central pore through which the larva breathes. ${ }^{1}$

LIFE CYCLE

The first instar is subcylindrical with circlets of small spines. The second stage is pyriform, with stronger stout spines on the globular portion and no spines on the narrow posterior part, which acts like a respiratory siphon. During larval life the wound continually oozes serous fluid or pus, but bacteriostatic activity in the gut of the larva seems to prevent undesirable overgrowth of pyogenic bacteria. The larval stage lasts from six to 12 weeks, with the larva feeding on tissue exudate. The mature larva (third instar) leaves the host and burrows into soil to pupate, emerging after four to 11 weeks. The larvae we removed were close to reaching this stage (figure 1 ). The adults live eight to nine days, never feed, and are sexually mature three hours after emergence. 
TECHNIQUES OF REMOVAL

There are several methods described to facilitate removal. ${ }^{23}$

The larva may be removed by enlarging the central punctum with a cruciate incision under local anaesthetic, grasping the larva with forceps, and teasing it out. Care must be taken not to damage the larva and so risk leaving parts behind in the wound, as this may result in a local foreign body reaction. This is the technique we successfully used.

Alternative methods rely on the fact that the larvae are obligate aerobes. Thus they can be coaxed into the open by occluding their air supply with adhesive tape, Vaseline, heavy makeup cream, or immersion of the affected part in oil. This results in the larvae struggling to the surface, when removal can be completed by grasping it with a fine forceps. Perhaps the most novel method of removal described is "bacon therapy". ${ }^{4}$ Multiple strips of raw bacon are placed over the nodule, with the fat occluding the central punctum. The larva migrates into the bacon over a period of hours sufficiently to allow its intact removal with forceps. These latter techniques minimise scarring. After removal of the larva, the lesions usually heal spontaneously without the need for routine antibiotic cover

\section{Comment}

As areas in south and central America become more and more popular as tourist destinations, infestations such as these with Dermatobia hominis which have long larval stages will present more frequently to $A \& E$ departments in the United Kingdom. They are often misdiagnosed as cellulitis, furunculosis, or infected sebaceous cysts. Diagnosis should be considered if there is a history of exposure and suggestive physical findings, as outlined above. Once the diagnosis is made, removal can be accomplished by the methods outlined.

We would like to thank Dr Richard Jennings, The Hospital of Tropical Diseases, London for valuable advice and assistance.

Manson-Bahr PEC, Bell DR. Manson's tropical diseases, 19th ed. London: Bailliere Tindall, 1987:1463-5.

Rooney S, Kerrigan D. Bot fly bite. Postgrad Med J 1993;69:411-3

Nunzi E Rogioletti F, Rebora A Removal of Dermatobia hominis larvae. Arch Dermatol 1986;122:140.

hominis lar. Arch Dermatol 1986;

E, Felsenstein D. Bacon therapy and furuncular myiasis. JAMA 1993;270:2087-8.

\section{A case of muscle abscess presenting to an accident and emergency department}

\section{Accident and \\ Emergency \\ Department, \\ Derriford Hospital, \\ Plymouth PL6 8DH \\ M A Howell \\ H R Guly \\ Correspondence to: \\ Mr M A Howell, Accident \\ and Emergency Department, \\ Bristol Royal Infirmary, \\ Marlborough Street, Bristol \\ BS2 8HW.}

Accepted for publication

13 November 1996

\begin{abstract}
A case is reported of a patient with acute primary muscle abscess who presented to the accident and emergency department with hip pain. Pyomyositis must be considered as a cause of muscle pain especially around the hip. A brief discussion of the diagnosis and management of pyomyositis is also presented.

(F Accid Emerg Med 1997;14:180-182)
\end{abstract}

Keywords: pyomyositis; hip pain

Accident and emergency (A\&E) departments often see patients with acute musculoskeletal pain. In this paper we present a case of acute muscle abscess (pyomyositis) presenting to an $A \& E$ department with hip pain and we briefly review the published reports on muscle abscesses.

\section{Case report}

A 46 year old previously healthy civil servant presented to the $A \& E$ department with a four day history of right hip and groin pain which had come on after playing table tennis. Rest and simple analgesics had been ineffective. On examination he had a temperature of $37.6^{\circ} \mathrm{C}$ and a tender right hip and pubic symphysis, with a reduced range of movement in the hip and inability to weight bear. Radiographs of the hip were normal, as was an ultrasound scan. A full blood count was unremarkable but the erythrocyte sedimentation rate (ESR) was increased at $32 \mathrm{~mm} / \mathrm{h}$. Blood cultures were taken and the patient admitted under the care of the A\&E team for rest and analgesia.

The blood cultures grew Staphylococcus aureus so flucloxacillin $2 \mathrm{~g}$ four times daily was started. The general condition of the patient improved but his reduced hip movement persisted, as did his pyrexia. The possibility of a psoas abscess was considered and a further ultrasound scan was performed four days after admission. This showed a $6 \mathrm{~cm}$ mass inferomedial to the right inguinal ligament, thought by the radiologist to be a strangulated hernia though the general surgeons did not think he had a hernia clinically. A computerised tomography (CT) scan the same day showed an inflamed right adductor brevis muscle. Liver function tests at this stage were deranged, and the patient was thought to be septicaemic. A 